\title{
Possible involvement of put $A$ gene in Helicobacter pylori colonization in the stomach and motility
}

\author{
Kazuhiko Nakajima ${ }^{1}$, Sakiko Inatsu ${ }^{2}$, Tomoko Mizote ${ }^{4}$, Yoko Nagata ${ }^{5}$, Kazue Aoyama ${ }^{2}$, Yoshihiro Fukuda ${ }^{3}$ \\ and Kumiko NaGATA ${ }^{6}$ \\ ${ }^{1}$ Department of Infection Control and Prevention, ${ }^{2}$ Department of Microbiology and ${ }^{3}$ Department of Clinical Nutrition and Health Sci- \\ ence, Hyogo College of Medicine, Mukogawa-cho, Nishinomiya, Hyogo 663-8501; ${ }^{4}$ Department of Human Science, Yamaguchi Prefec- \\ tural University, 3-2-1 Sakura Batake, 753-8502, Yamaguchi; ${ }^{5}$ Department of Materials and Applied Chemistry, College of Science and \\ Technology, Nihon University, 1-8-14 Kanda Surugadai, Chiyoda-ku, Tokyo 101-8308; and ${ }^{6}$ Department of Food and Nutrition, Faculty \\ of Human Life Sciences, Senri Kinran University. 5-25-1 Fujishirodai, Suita, Osaka 565-0873, Japan
}

(Received 27 August 2007; and accepted 10 November 2007)

\begin{abstract}
H. pylori is a gram-negative bacterium associated with gastric inflammation and peptic ulcer and considered a risk factor for gastric cancer in its natural habitat. However, the energy metabolism of $H$. pylori in the stomach remains to be clarified. H. pylori shows rather high respiratory activity with L-proline and significantly large amounts of L-proline are present in the gastric juice from $H$. pylori infected patients. We constructed a disrupted mutant of the put $A$ gene, which encodes the proline utilization A (Put A) flavin-linked enzyme, in order to examine the role of put $A$ in the gastric colonization of $H$. pylori. The put $A$ disrupted mutant, $\triangle p u t A$, was constructed by inserting a chloramphenicol resistant gene into put $A$. $\Delta$ put $A$ did not show respiratory activity using L-proline and could not incorporate L-proline into cells. $\Delta$ put $A$ also did not show motility in response to amino acids and did not display the swarming activity observed with the wild-type. $\Delta p u t A$ had lost its ability to colonize the stomach of nude mice, an ability possessed by the wild-type. These findings indicate that put A may play an important role in H. pylori colonization on the gastric mucus layer.
\end{abstract}

Helicobacter pylori is a gram-negative bacterium associated with gastric inflammation and peptic ulcer and is a risk factor for gastric cancer $(4,8,27,32)$. The natural habitat of $H$. pylori is the mucus layer on the human gastric epithelium, where it is considered to survive for more than ten years. This microaerophilic bacterium does not catabolize saccharides (19), and the preferred energy substrate is not glucose $(20,21)$ but organic acids and amino acids.

Address correspondence to: Dr. Kumiko Nagata, Department of Food and Nutrition, Faculty of Human Life Sciences, Senri Kinran University. 5-25-1 Fujishirodai, Suita, Osaka 565-0873, Japan

Tel: +81-6-6872-7842, Fax: +81-6-6872-7872

E-mail: k-nagata@kinran.ac.jp
However, the energy metabolism of $H$. pylori in its natural habitat has not been clarified. We previously reported that $H$. pylori shows rather strong respiratory activity when amino acids such as L-proline, L-serine and L-alanine are used as respiratory substrates (22). We also reported that the gastric juice of patients infected with $H$. pylori contained rather large amounts of these amino acids, especially L-proline (22). Thus, we proposed that $H$. pylori may utilize these amino acids as energy sources in the stomach.

Recently, Guszczyn et al. reported that a free-proline pool is present in human gastric tissue, where there are extremely large amounts of proline, $10 \mathrm{mg}$ per g of gastric tissue (9). Since the gastric tissue contains much prolidase, this proline seemed to 
have been driven out from the collagen in gastric tissues (9). Kavermann et al. demonstrated that $H$. pylori cells secreted collagenase which is encoded by a gene, hp0169 of H. pylori (14). They also described collagenase as being essential for gastric colonization of $H$. pylori (14). In addition, the growth of $H$. pylori was reported to be enhanced by addition of L-proline together with L-alanine to Dulbecco's modified Eagle's minimal essential medium (33). These reports suggest that there are large amounts of proline in the deeper part of the gastric mucus layer, the primary habitat of $H$. pylori. This offers support for our proposal that $H$. pylori cells predominantly utilize L-proline as an energy source (8).

Proline is converted to glutamate in two successive steps by the proline utilizing A (Put A) flavinlinked enzyme in gram-negative bacteria. Put A contains a proline dehydrogenase (EC 1.5.99.8) domain that catalyzes the flavin adenine dinucleotidedependent oxidation of proline to $\Delta^{1}$-pyrroline-5carboxylate (P5C) and a P5C dehydrogenase (EC 1.5.1.12) domain that catalyzes the $\mathrm{NAD}^{+}$-dependent oxidation of P5C to glutamate. The gene put A encodes both proline dehydrogenase and P5C dehydrogenase in many gram-negative bacteria including $H$. pylori $(3,10,15-17,30,34)$. In the present work, we constructed a disrupted mutant of put $A$ and investigated the role of put $A$ in $H$. pylori colonization in the stomach of the nude mouse. The put $A$ disrupted mutant, $\triangle p u t A$, was constructed from two strains of H. pylori, ATCC 43504 and HPK-5 by insertion of a chloramphenicol resistant gene into the middle of put $A$. The results showed that the $\Delta p u t A$ mutant from the two strains did not display respiratory activity of L-proline because the mutant had lost the activity of proline dehydrogenase which is essential for proline respiration. H. pylori displays rather high respiratory activity with L-proline, and hydrogen derived from L-proline by L-proline dehydrogenase probably participates in ATP production via the respiratory chain of $H$. pylori as described previously (22). Interestingly, the $\Delta p u t A$ from both strains had little motility and did not show swarming activity. In addition, no colonization occurred in the stomach of nude mice infected with this mutant. The motility of $H$. pylori is one of the important virulent factors, as no colonization in the stomach is observed in mice infected with a strain with disrupted flagella (6). Thus, the failure of $\Delta p u t A$ to cause colonization may be due to its loss of motility.

This is the first report to suggest that the put $A$ gene related to L-proline respiration may be essen- tial for the motility necessary for $H$. pylori to colonize the gastric mucus layer.

\section{MATERIALS AND METHODS}

Bacterial strains and culture conditions. The strains of $H$. pylori used in the present study, ATCC 43504 and HPK-5 (31), were cultured in Brucella broth (Becton Dickinson, Cockeysville, MD, USA) containing 5\% horse serum (Donor Horse Serum manufactured by Thermo Trace Ltd., Melbourne, Australia) under $10 \% \mathrm{CO}_{2}$ in an incubator with gentle shaking at $37^{\circ} \mathrm{C}$ for $20 \mathrm{~h}$ as described previously. Escherichia coli JM109 was used for the sub-cloning of put A. E. coli was cultured in Luria-Bertani broth or agar medium supplemented with kanamycin $(50 \mu \mathrm{g} / \mathrm{mL})$ or chloramphenicol $(30 \mu \mathrm{g} / \mathrm{mL})$ at $37^{\circ} \mathrm{C}$.

DNA techniques. DNA and plasmid purification, and cloning procedures were performed as described previously (5). H. pylori genomic DNA was extracted with a Genomic DNA Extraction Miniprep System (VIOGENE, Sunnyvale, CA, USA). Plasmid DNA was prepared and purified by using a Miniprep plasmid extraction kit (Bio Rad, CA, USA). PCR was performed with a TaKaRa PCR Thermal Cycler MP (TAKARA BIOINC., Shiga, Japan). Oligonucleotide primers were synthesized by Texas Genomics, Japan.

Construction of $\triangle p u t$ A mutant of $H$. pylori. Primers 56F1 (5'-ATGCAAAAAATCATTGACGATTCGC TAG-3') and 56R1 (5'-TTTTCAGCACAGCAT GATTTGTGGCAAG-3') were designed based on the H. pylori 26695 strain and used for cloning of put $A$. The Xho I restriction site of pCRXL cloning vector (Invitrogen, Carlsbad, CA, USA) was deleted by inserting a DNA fragment (5'-TCGACGTC GA-3'). Next, the Xho I-site was inserted into the middle of put $A$, and pCRXL:put $A$ was amplified by PCR with the primer pair of 56XHOF (5'-GA GCTTTACCCAGAGATGGATGGGAGGTTTGAA GAT-3') and 56XHOR (5'ATCCATCTCTGGGTA AAGCTCGAGTTAAAATAGGAGCGTTACG CAT-3'). The green fluorescent protein:chloramphenicol (GFP. Cm) cassette was inserted into the Xho I site. The recombinant plasmid was then introduced into $H$. pylori by natural transformation via allelic exchange, and chloramphenicol-resistant colonies were isolated. These genomic mutants were confirmed by Southern blotting methods and DNA sequencing. 
(a)

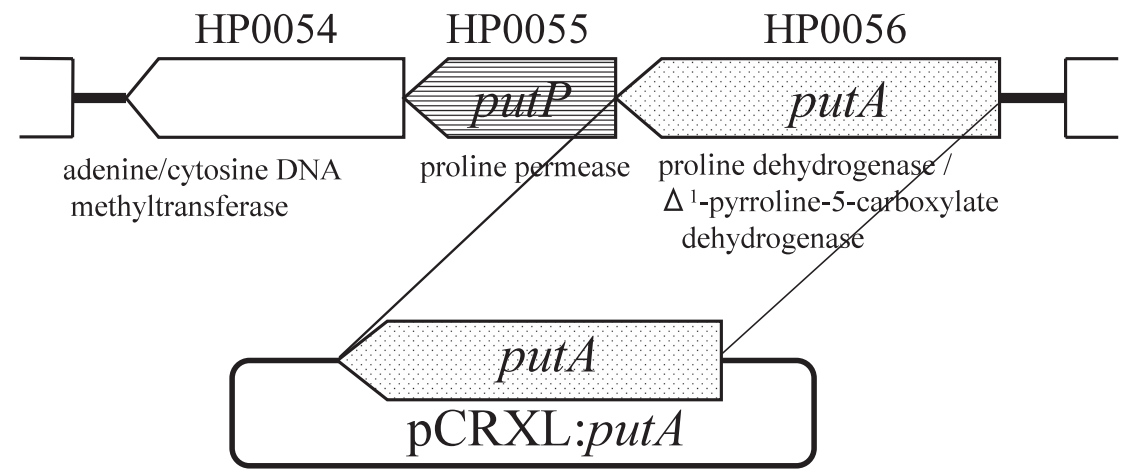

(c)

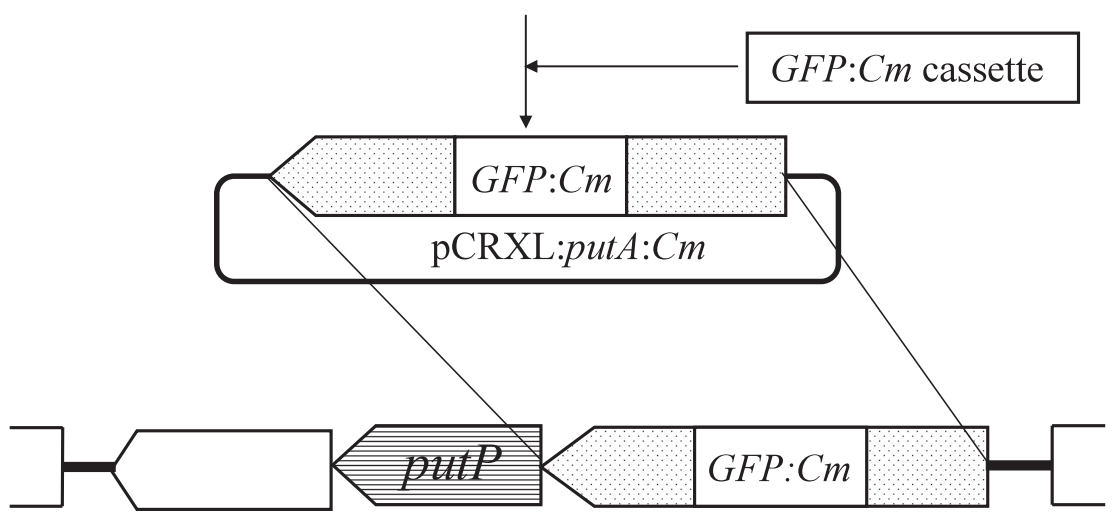

Fig. 1 DNA constructions. (a) Schema of put $A$ (HP0055) and put $P$ (HP0056) genes locations in wild type, 26695 strain. (b) Put $A$ was amplified by PCR and inserted into PCRXL cloning vector. (c)GFP:Cm cassette was inserted into the middle of the amplified put $A$ gene of pCRXL:put $A$ vector. (d) Isogenic put $A$ disrupted mutants of ATCC43504 and HPK5 were obtained by allelic exchanged mutagenesis with pCRXL:put $A: G F P$ vector.

Assay of 2,6-Dichlorophenolindophenol (DCIP) reducing and respiratory activities by $H$. pylori whole cells. H. pylori cells were added to the reaction mixture containing $50 \mathrm{mM}$ phosphate buffer ( $\mathrm{pH} 7.0$ ), $0.01 \mathrm{M}$ sodium azide, $10 \mathrm{mM}$ L-proline and $50 \mu \mathrm{M}$ DCIP. After $10 \mathrm{~min}$ incubation at $37^{\circ} \mathrm{C}$, the cells were removed by centrifugation at $10,000 \times g$ for $5 \mathrm{~min}$ and then A600 of the supernatant was measured using DU 640, Beckman, Fullerton, USA. An $\varepsilon_{600}$ of $21.6 \mathrm{mM}^{-1} \mathrm{~cm}^{-1}$ was used as described previously (22).

Cultured H. pylori cells were harvested by centrifugation at $3,500 \times g$ for $10 \mathrm{~min}$ at room temperature, and suspended in $10 \mathrm{mM}$ Hepes buffer $(\mathrm{pH} 7.0)$ containing $0.9 \% \mathrm{NaCl}$. Respiration of whole cells $\left(1 \times 10^{8}\right.$ cells $\left./ \mathrm{mL}\right)$ was monitored polarographically using a Clark-type oxygen electrode (YSI Inc., Yellow Springs, OH, USA) in a semiclosed vessel containing the same buffer as above at $37^{\circ} \mathrm{C}$ as described previously (22). Various substrates were added to the oxygen electrode vessel with a syringe. Respiratory activity (oxygen uptake) was determined from polarographic traces of the oxygen electrode as described previously (22).
Incorporation of L-proline into wild-type and $\Delta$ put $A$ cells of $H$. pylori. Cultured $H$. pylori cells from wild-type and $\triangle p u t$ A of ATCC 43504 were harvested by centrifugation as described above. Cells $(1 \times$ $10^{8}$ ) were suspended in one mL of Ham's F-12 medium prepared according to Gibco Catalog No. 21700 with bicarbonate. Five bottles of $20 \mathrm{~mL}$ tissue culture bottles, each containing $5 \mathrm{~mL}$ of the cell suspension, were cultured microaerobically at $37^{\circ} \mathrm{C}$ with gently shaking. Cells were harvested at 0,5 , 10,24 and $30 \mathrm{~h}$, then centrifuged at $3,500 \times g$ for $10 \mathrm{~min}$ at room temperature to obtain the cell-free supernatant. The amount of L-proline in the supernatant was assayed as described previously (22).

Determination of free-amino acids in wild-type and $\Delta$ put $A$ cells of $H$. pylori. Wild-type and $\Delta$ put $A$ cells from $H$ pylori ATCC 43504 were cultured in Brucella broth containing 5\% of horse serum as described above. After $20 \mathrm{~h}$ cultivation, cells were harvested by centrifugation. The amounts of free-amino acids present within cells of both the wild-type and $\Delta p u t A$ strains were assayed as described previously (22). 
Assay of the motility responding to amino acids in $H$. pylori whole cells. H. pylori cells grown microaerobically were collected and washed twice with $50 \mathrm{mM}$ Na-K phosphate buffer (pH 7.0) containing $0.1 \mathrm{mM} \mathrm{MgSO}_{4}$. Various kinds of amino acids (1 $\mathrm{mM}$, final concentration) were added to the same buffer described above containing whole cells $(1 \times$ $10^{7}$ cells $/ \mathrm{mL}$ ). A total of $80 \mu \mathrm{L}$ of the cells was placed into the chamber covered with a glass slip. The response of each bacterial strain to the amino acids on the thermoplate (MATS-555F, Olympus, Japan) was observed using a microscope.

Assessment of swarming activity. The swarming in a soft-agar plate containing Brucella broth, 5\% horse serum, $0.3 \%$ agar and $0.8 \%$ gelatin was assayed. $H$. pylori ATCC 43504 cells cultured with the Brucella broth described above were centrifuged, and the resulting pellet was pressed onto the soft agar plate. After 3-4 days of cultivation as described above, the swarming was assessed from the diameter size of the colony.

Electron microscopy. The morphology of flagella from wild-type and $\Delta$ put A $H$. pylori ATCC 43504 was examined by scanning electron microscopy (SEM) and transmission electron microscopy (TEM). H. pylori strains were cultured with Brucella broth as described above. For SEM, samples were prepared by fixing $H$. pylori cells in $1 \%$ glutaraldehyde, and washed with $0.1 \mathrm{M}$ sodium cacodylate buffer ( $\mathrm{pH}$ 7.2) over-night at $4^{\circ} \mathrm{C}$. The samples were then dehydrated using a graded acetone series (30, 50, 70, 95 and 100\%). Subsequently, the samples were dried with a critical point dryer (HCP-1; Hitachi, Ibaragi, Japan) and sputter-coated with gold palladium (E-5150; Polaron, Watford, U.K.). Images of the cells were obtained with SEM (S-800; Hitachi, Tokyo, Japan). For TEM, the cells were negatively stained as described previously (11). The cells were then mounted on polyvinyl formvar membrane and negatively stained with $2 \%$ uranyl acetate. Images of the cells were scanned by an electron microscope (H-7100; Hitachi, Tokyo, Japan).

Infection of nude mice with wild-type and $\Delta p u t$ A. Female Balb/c nude mice aged 6 weeks (Japan SLC, Inc., Shizuoka, Japan) were used. Wild-type and $\Delta$ put $A$ cells from ATCC 43504 or HPK-5 were orally administered with $1 \times 10^{8}$ cells to mice after $12 \mathrm{~h}$ of fasting, twice with a three-day interval. Five mice of each strain were infected, and the stomachs were obtained after 4 weeks. Colony forming unit
(CFU) tests were carried out to assess the colonization in the stomachs of the mice as described previously (29).

Determination of protein. The amount of protein in $H$. pylori cells was determined by a modification of the Lowry procedure (18).

\section{RESULTS}

DCIP reducing and respiratory activities in wildtype and $\triangle$ put $A$ cells from $H$. pylori

$\triangle$ put $A$ mutant from ATCC 43504 and HPK-5 completely lacked the activity of L-proline dehydrogenase which reduces DCIP using hydrogen from L-proline as shown in Table 1. H. pylori has a gene encoding D-amino acid dehydrogenase ( $\operatorname{dad} A)$, which reduces also DCIP using hydrogen from $\mathrm{D}$-proline or D-alanine. The $\Delta p u t A$ from these two strains had DCIP-reducing activities of D-proline and D-alanine at almost the same levels as those of their wild strains (Table 1).

Respiratory activity by L-proline depends on L-proline dehydrogenase in $H$. pylori. The $\Delta p u t A$ from these two strains did not display respiration by L-proline as shown in Table 2, while respiratory activities of other amino acids, such as L and D isomers of alanine and L-serine did not show any significant difference between the $\Delta p u t A$ and the wild-type of ATCC 43504 and HPK-5.

Utilization of proline in wild-type and $\Delta$ put $A$ of $H$. pylori

H. pylori has a gene of put $P$ which encodes a proline permease responsible for the incorporation of proline into whole cells. Since put $P$ is situated downstream of put $A$, the disruption of put $A$ may affect the transcription of put $P$. We examined proline-incorporation into cells in both the $\triangle p u t A$ and the wild-type of ATCC 43504 by using Ham's F-12 which is a medium containing defined ingredients. With the wild-type, the amounts of proline in the medium decreased time-dependently during incubation at $37^{\circ} \mathrm{C}$, and proline almost disappeared after $24 \mathrm{~h}$ incubation as shown in Fig. 2. However, the amounts of proline in the medium did not change in the case of $\Delta$ put $A$ (Fig. 2). These results suggest that $\triangle p u t A$ seems to have lost the transcribing activity possessed by put $P$.

Proline is not an essential amino acid for the growth of $H$. pylori (28), indicating that $H$. pylori has an enzyme system involved in the de novo synthesis of proline. In fact, $\Delta p u t A$ cells contain a 
Table 1 DCIP reduction* by wild-type and $\triangle$ put $A$ of $H$. pylori cells with $D$ and $L-$ isomers of proline and alanine as substrates

\begin{tabular}{ccccc}
\hline \multirow{2}{*}{ Substrate } & \multicolumn{2}{c}{ ATCC43504 } & \multicolumn{2}{c}{ HPK-5 } \\
\cline { 2 - 5 } & wild-type & $\Delta$ put A & wild-type & $\Delta$ put A \\
\hline L-Proline & 7.41 & 0.00 & 6.90 & 0.00 \\
D-Proline & 6.30 & 5.75 & 6.40 & 5.35 \\
D-Alanine & 5.46 & 6.42 & 7.21 & 7.01 \\
\hline
\end{tabular}

*DCIP reduction : nmol DCIP reduced / $\mathrm{min} / \mathrm{mg}$ protein

Table 2 Respiration* by wild-type and $\Delta$ put $A$ of $H$. pylori cells with $D$-and $L$ - isomers of alanine, proline, and serine as substrates

\begin{tabular}{lcccc}
\hline \multirow{2}{*}{ Substrate } & \multicolumn{2}{c}{ ATCC43504 } & \multicolumn{2}{c}{ HPK-5 } \\
\cline { 2 - 5 } & wild-type & $\Delta p u t A$ & wild-type & $\Delta p u t A$ \\
\hline L-Alanine & 29.8 & 34.5 & 31.7 & 36.3 \\
D-Alanine & 12.8 & 14.1 & 24.1 & 23.0 \\
L-Proline & 36.6 & 0.0 & 32.2 & 0.0 \\
D-Proline & 27.2 & 18.9 & 28.1 & 21.7 \\
L-Serine & 43.4 & 48.6 & 57.2 & 46.0 \\
D-Serine & 8.9 & 14.1 & 13.3 & 15.4 \\
\hline
\end{tabular}

*Respiration:nmol oxygen / min / mg protein

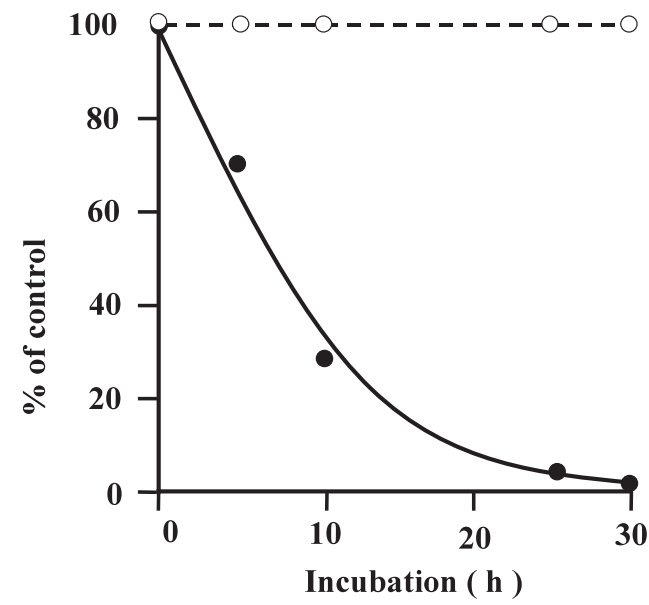

Fig. 2 Incorporation of L-proline into wild-type and $\triangle$ put $A$ of $H$. pylori ATCC 43504. Closed circles with solid line and open circles with dotted line show wild-type and $\Delta$ put $A$, respectively. Experimental protocol is described in MATERIALS AND METHODS. Percentage of control was determined using the following equation: percentage $=$ (amounts of L-proline in Ham's medium F-12) (amounts of L-proline in cell-free supernatant of culture medium after 0,5 , $10,24$ and $30 \mathrm{~h})^{-1}(100)$

large amount of proline (Fig. 3), suggesting that put $A$ disruption does not seem to affect on the biosynthesis of proline. While the wild-type cells had only a small amount of proline, their amounts of glutamate were significantly higher than those in $\Delta p u t A$ cells (Fig. 3). These results suggested that wild-type cells dominantly metabolized L-proline into glutamate with their dehydrogenase. Unlike the cases of proline and glutamate, the amounts of other amino acids such as alanine, serine and aspartate did not show significant difference between the wild-type and the $\Delta p u t A$ strains (Fig. 3). These results offer support for proline being dominantly used as a respiratory substrate in the wild-type $H$. pylori, but not in $\Delta p u t A$.

Motility responding to amino acids in wild-type and $\triangle$ put A of H. pylori

H. pylori ATCC 43504 cells showed that their motility responded to amino acids depending on their type as can be seen from Table 3. H. pylori cells showed motile activity responding to alanine, proline, serine, and aspargine. Among these amino acids, $H$. pylori showed the strongest motile activity with proline. However, $\Delta$ put $A$ showed no motility with respect to proline, and only a little motility in response to other amino acids (Table 3). Although the data are not shown, almost the same results as those for the ATCC 43504 strain were obtained for HPK-5.

As $H$. pylori displays swarming activity, we examined this activity of $\triangle p u t A$ from ATCC 43504 on the plate containing Brucella soft agar. The $\Delta p u t A$ formed a much smaller zone of swarming, unlike the case of the wild-type (Fig. 4). 


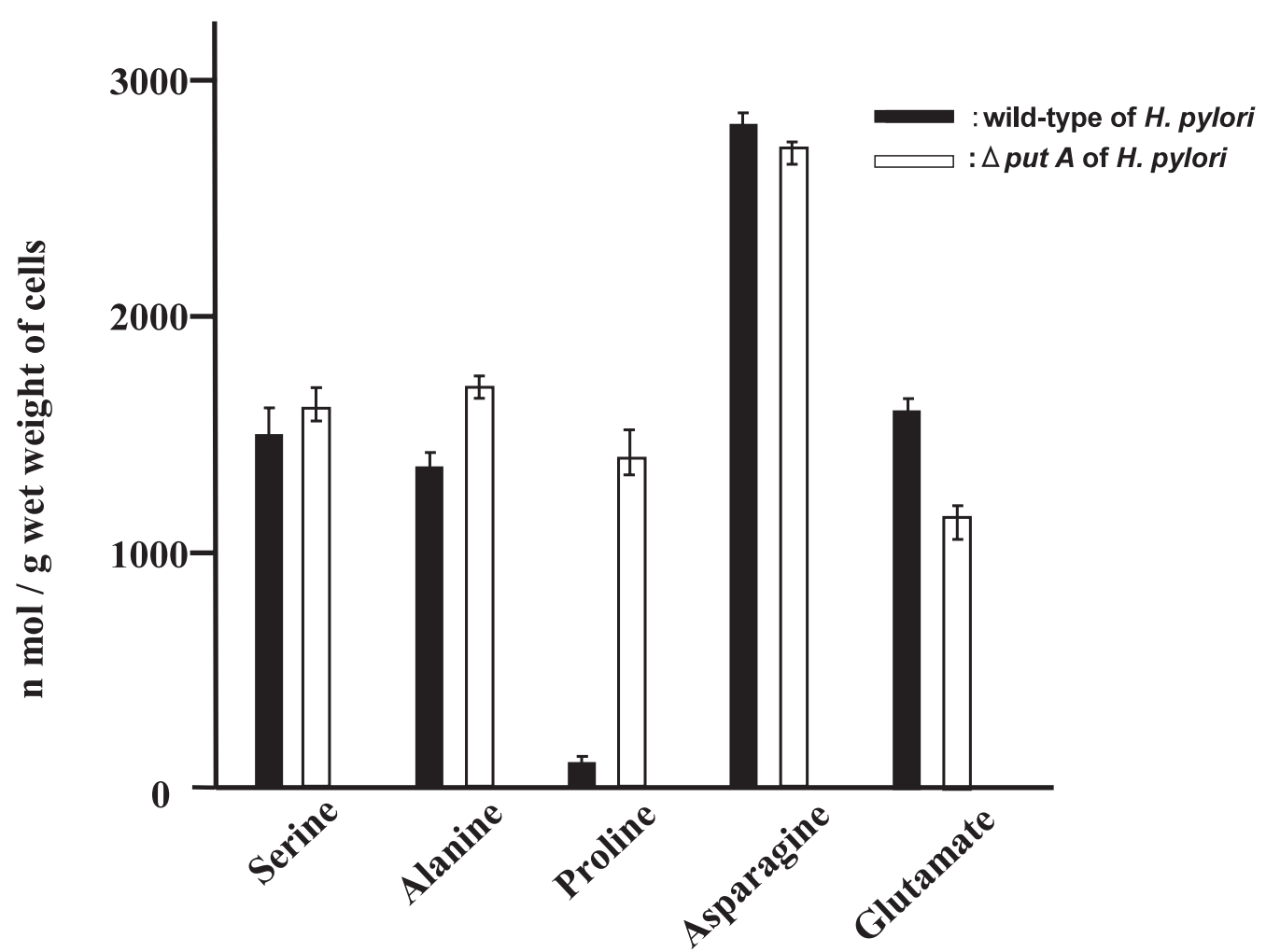

Fig. 3 Amount of free amino acids in cells of wild-type and $\triangle$ put $A$ of $H$. pylori ATCC 43504. Closed and open bars show wild-type and $\triangle$ put $A$, respectively. Experimental protocol is described in MATERIALS AND METHODS.

Table 3 Motility responding to various amino acids in wildtype and $\triangle$ put $A$ of $H$. pylori ATCC43504 cells

\begin{tabular}{|c|c|c|}
\hline \multirow{2}{*}{ Amino acid } & \multicolumn{2}{|c|}{ H. pylori ATCC43504 } \\
\hline & wild-type & $\Delta p u t A$ \\
\hline Alanine & +++ & \pm \\
\hline Serine & +++ & \pm \\
\hline Proline & +++++ & - \\
\hline Asparagine & +++ & \pm \\
\hline
\end{tabular}

Cells under a microscope were showing non motile activity $(-)$, and $<10 \%( \pm)$, about $60 \%(+++)$ and $>90 \%(+++++)$ of cells under a microscope were showing motile activity.

Electron microscopic observation of flagella of wildtype and $\triangle p u t A$

Since the motility of $H$. pylori depends on the presence of flagella, we compared the morphology of the flagella between the wild-type and the $\Delta p u t A$ from ATCC 43504 by electron microscopy. As shown in Fig. 5, the flagella of $\Delta p u t A$ seem to exist (d), but full-length sheathed flagella like those of the wild-type $(\mathbf{b}, \mathbf{c})$ were rarely observed. Instead, the flagella of $\Delta p u t A$ were short in length and seemed to be deformed $(\mathbf{e}, \mathbf{f})$, therefore, they were very difficult to identify as flagella.

\section{ATCC43504}

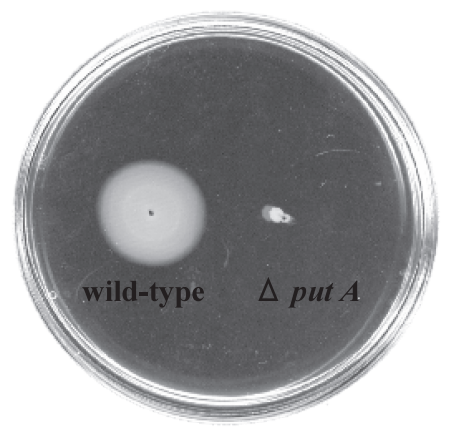

Fig. 4 Swarming abilities of wild-type and $\Delta$ put $A$ of $H$. pylori ATCC 43504. Experimental protocol is described in MATERIALS AND METHODS.

Colonization of wild-type and $\Delta p u t A$ in the stomach of nude mice infected with $\mathrm{H}$. pylori

Nude mice have been used as an experimental model for $H$. pylori colonization in stomach infection (13). To examine whether $\Delta p u t A$ can or can not display colonization with this model, the animals were infected with either wild-type or $\Delta p u t A$ of ATCC 43504. The CFU test was used to estimate the colonization in the stomach after 4 weeks of infection. As shown in Fig. 6, positive CFU in four of 

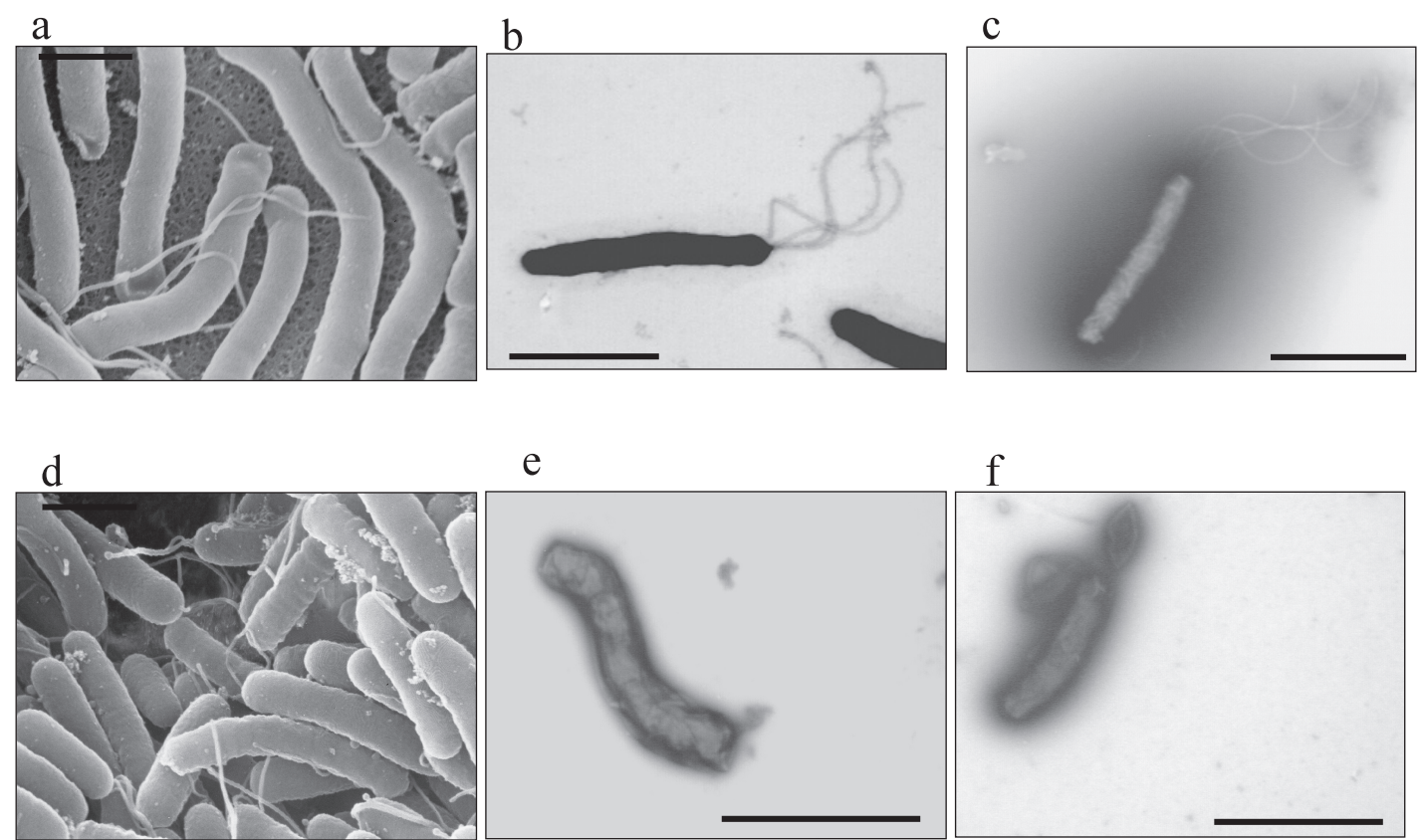

e

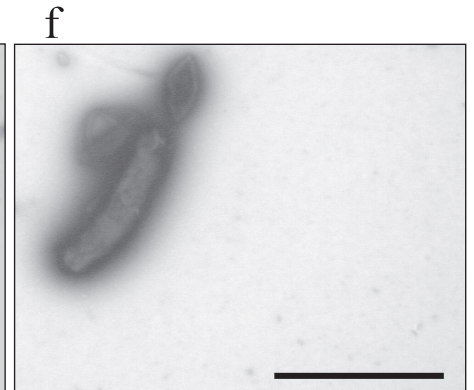

Fig. 5 Flagella of wild-type (a-c) and $\triangle$ put $A$ (d-f) of $H$. pylori ATCC 43504 by scanning (SEM) and transmission electron microscope (TEM). a and d: SEM images. b, c, e and f: TEM images after negative staining. Bars show $2 \mu \mathrm{m}$.

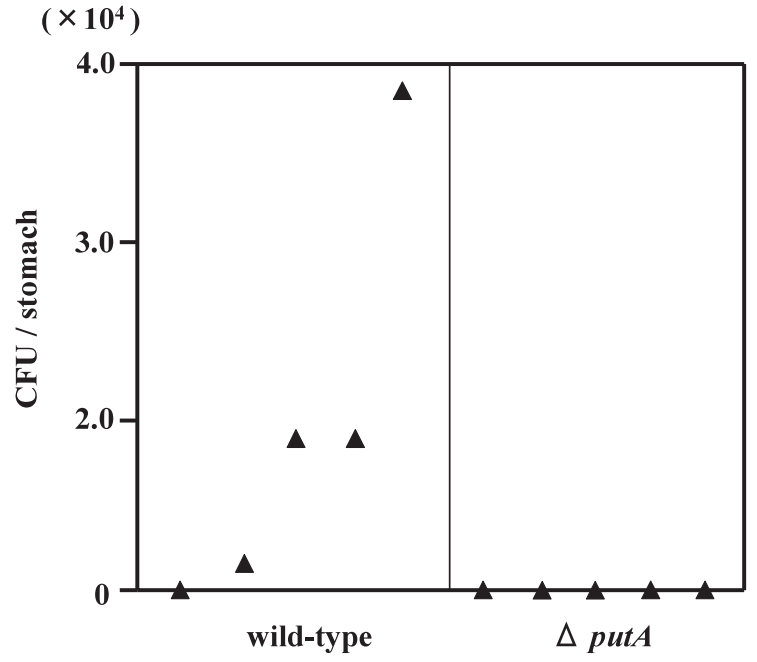

Fig. 6 Colonization of wild-type and $\triangle$ put $A$ of $H$. pylori ATCC 43504 to nude mice. Five mice per group were infected either with wild-type or $\triangle$ put $A$ of the $H$. pylori. Each point shows CFU per stomach of a mouse. Other experimental protocols are described in MATERIALS AND METHODS.

five mice was observed in the case of the wild-type from ATCC 43504, but not at all for the $\Delta p u t A$ mutant. Although data are not shown, the stomach from mice infected with wild-type as well as $\Delta p u t$ of HPK-5 did not show positive CFU.

\section{DISCUSSION}

Several potential factors including urease, cag A, flagella and chemotactic factors have been reported to be involved in the colonization of $H$. pylori in the stomach of animals $(6,7,24)$. However, little work has been done on the colonization of $H$. pylori related to energy metabolism using disrupted mutant strains. Olson and Maier reported recently that $H$. pylori cells used molecular hydrogen as an energy source in mice (26). In their study, the hydrogenasedisrupted mutant did not display colonization in the stomach of mice, where there are many kinds of anaerobic bacteria present at a high density and the molecular hydrogen derived from these anaerobic bacteria seems to be abundant.

In humans unlike in mice, there are few bacteria in the stomach. Since the habitat of $H$. pylori is the gastric mucus layer, various amino acids diffusing from the stomach juice may be utilized by $H$. pylori as an energy source. In our previous report, we showed that human stomach juice contains significant amounts of amino acids such as proline, alanine and serine that can be utilized by H. pylori as respiratory substrates (22). We also reported a significantly high content of L-proline in the stomach juice from $H$. pylori infected patients. This led us to propose that $H$. pylori may predominantly use L-proline for an energy source in the human stom- 
ach. Support for our hypothesis comes from recent reports. For example, human stomach tissue contains extremely high amounts of free-proline which seems to be derived from collagen in the tissue (9). Also, H. pylori cells secrete their own collagenase outside cells, and this enzyme is essential for the colonization in the H. pylori infected mouse (14). Collagen, which is present in the extracellular matrix of the stomach, is probably degraded by collagenase and prolidase, resulting in the production of free-proline in stomach tissue. H. pylori cells adhere near the tight junctions of the gastric epithelial cells $(11,25)$. This specific location on the epithelium is thought to be favored by $H$. pylori due to the proximity of bacterial nutrients released by the host tissue. Thus, a niche for $H$. pylori could be expected to contain large amounts of L-proline which has diffused from the stomach tissue. As a result, $H$. pylori cells may utilize L-proline predominantly as a respiratory substrate for an energy source.

In the present work, we have shown that a gene, put $A$, may play an important role in the colonization of $H$. pylori. Put A encodes two enzymes, proline dehydrogenase and P5C dehydrogenase. Put $A$ was disrupted by insertion of a $\mathrm{Cm}$ resistant gene into its middle section using plasmid pCR-XL (Fig. 1). The disrupted mutant of put $A$ from two kinds of H. pylori strains, ATCC 43504 and HPK-5 did not show respiratory activities of L-proline as well as L-proline dehydrogenase which reduces DCIP using L-proline (Table 1). The $\Delta p u t A$ mutant from ATCC 43504 did not colonize the stomach of nude mice infected with these strains, although its wild strain could (Fig. 6). The loss of this ability by $\Delta p u t A$ seems to be due to the following two reasons: (1) the $\Delta p u t A$ from the two strains lost respiratory activity with L-proline because of the lack of L-proline dehydrogenase activity (Tables 1 and 2) and (2) cells of $\Delta p u t A$ were nonmotile, showing no swarming activity (Fig. 4).

Motility has been shown to be a key factor in the ability of $H$. pylori to colonize the gastric mucosa (7, 14). Because the gastric mucous gel layer has a rapid turnover, H. pylori cells proliferating in the mucous layer need the ability to move toward the epithelial cell surface against the mucous flow toward the duodenum. We have shown here that $H$. pylori exhibited motility responding to various kinds of amino acids. Among the amino acids utilized by $H$. pylori as respiratory substrates, the wild-type strain of ATCC 43504 and HPK-5 showed strong motility responding to proline (Table 3). However, the $\Delta p u t$ $A$ of these strains had completely lost their motility responding to proline, and showed little motility in response to other amino acids (Table 3 ). As a result, $\Delta p u t A$ from ATCC 43504 had lost its swarming activity (Fig. 4). The flagella of $\Delta p u t A$ seemed to be deformed when compared with those of the wildtype (Fig. 5, e, f). These results suggest that the decreased motility of $\Delta p u t A$ is due to its deformed flagella (Fig. 5, e, f).

Motility and chemotaxis are delicate phenomena and seem to be affected by many environmental factors such as metabolic substances, temperature, oxygen and cell density. Motility is considered to impose a physiological cost, and has been estimated to be about $2 \%$ of the total energy expenditure for an enteric bacterial species (12). Proline plays a central role in energy metabolism and can serve as an important energy source for various kinds of enteric bacteria (2). H. pylori ATCC 43504 wild strain consumed L-proline rapidly in the Ham's F-12 medium (Fig. 2). Cells of wild-type H. pylori cultured in Brucella broth contained small amounts of proline (Fig. 3). Since the amounts of glutamate which is a product of proline respiration were significantly higher in the wild-type than in $\Delta p u t A$ (Fig. 3), proline seems to be used as the main respiratory substrate in H. pylori. Thus, the lack of proline respiration by $\triangle p u t A$ might be another reason for the decreased motility of this mutant.

In the H. pylori 26695 strain, put $A$ and put $P$ are coded at HP0056 (3558 bp) and HP0055 (1491 bp), respectively. Put $P$ is located downstream in the same direction from the promoter region of put $A$, and $15 \mathrm{bp}$ at the beginning of put $P$ overlaps with $15 \mathrm{bp}$ at the end of put $A$. Our present work has shown that put $P$ encoding L-proline permease did not seem to be transcribed since the disruption of put $A$ caused loss of the ability to incorporate L-proline into cells (Fig. 2). These results demonstrated that put $A$ and put $P$ are co-regulated genetically as one operon.

Put A consisting of two domains, those of proline dehydrogenase and P5C dehydrogenase, is a relatively large polypeptide enzyme containing 1,185 amino acids in E. coli (35). As Put A and Put P have been reported to be membrane-bound in gramnegative bacteria $(1,3)$, those of $H$. pylori are also likely to be membrane-bound. Thus, the loss of Put A together with Put P may affect other protein expressions participating in the motility of $H$. pylori, and result in morphological changes of the flagella. Further study, e.g. using proteome analysis, is needed to clarify which protein(s) other than Put A or Put $\mathrm{P}$ is (are) affected by the disruption of put $A$. 
Kavermann et al. reported that put $P$ was one of essential genes for gastric colonization in an animal model infected with $H$. pylori (14). Our present works has shown that $\Delta p u t A$ failed to show colonization in the infected mice (Fig. 6), although there is a possibility that faster clearance of $\Delta p u t A$ than the wild-type appeared in the infected mice. Thus, it may be possible to develop the $\Delta p u t A$ of $H$. pylori as a useful vaccine.

\section{Acknowledgment}

We are indebted to Dr. Tamura for his valuable discussions. We thank Dr. Nakazawa for providing the HPK-5 strain, and Ms Sakaedani for helping with the CFU test. This research was financially supported by Grants-in-Aid for Researchers from the Hyogo College of Medicine Foundation.

\section{REFERENCES}

1. Abrahamson JLA, Baker LG, Stephenson JT and Wood JM (1983) Proline dehydrogenase from Escherichia coli K 12, properties of the membrane-associated enzyme. Eur $J$ Biochem 134, 77-82.

2. Adams E and Frank L (1980) Metabolism of proline and the hydroxyprolines. Annu Rev Biochem 49, 1005-1061.

3. Allen SW, Sentis Willis A and Maloy SR (1993) DNA sequence of the put A gene from Salmonella typhimurium: a bifunctional membrane-associate dehydrogenase that binds DNA. Nucleic Acids Res 21, 1676.

4. Blaser MJ (1990) Helicobacter pylori and the pathogenesis of gastroduodenal inflammation. J Infect 161, 626-633.

5. Copass M, Grandi G and Rappuoli R (1997) Introduction of unmarked mutation in the Helicobacter pylori vacA gene with a sucrose sensitivity marker. Infect Immun 65, 19491952.

6. Eton KA (1999) Animal models of Helicobacter gastritis. Curr Top Microbiol Immunol 241, 132-154.

7. Figura N, Trabalzini L, Mini R, Bernardini G, Scaloni A, Talamo F, Lusini P, Ferro E, Martelli P and Santucci A (2004) Inactivation of Helicobacter pylori cagA gene affects motility. Helicobacter 9, 185-193.

8. Graham DY, Lew GM, Klein PD, Evans DG, Evans Jr DJ, Saeed ZA and Malaty HM (1992) Effect of treatment of Helicobacter pylori infection on the long-term recurrence of gastric or duodenal ulcer. A randomized, controlled study. Ann Intern Med 116, 705-708.

9. Guszczyn T and Sobolewski K (2004) Deregulation of collagen metabolism in human stomach cancer. Pathobiology 71, 308-313.

10. Jimenez-Zurdo JI, Garcia-Rodriguez FM and Toro N (1997) The Rhizobium meliloti put $A$ gene: its role in the establishment of the symbiotic interaction with alfalfa. Mol Microbiol 23, 85-93.

11. Josenhans C, Labigne A and Suerbaum S (1995) Comparative ultrastructural and functional studies of Helicobacter pylori and Helicobacter mustelae flagellin mutants: both flagellin subunits, FlaA and FlaB, are necessary for full motility in Helicobacter species. J Bacteriol 177, 3010-3020.
12. Josenhans C and Suerbaum S (2002) The role of motility as a virulence factor in bacteria. Int J Med Microbiol 291, 605614.

13. Karita M, Kouchiyama T, Okita K and Nakazawa T (1991) New small animal model for human gastric Helicobacter pylori infection: success in both nude and euthymic mice. Am J Gastroenterol 86, 1596-1603.

14. Kavermann H, Burns BP, Angermuller K, Odenbreit S, Fischer W, Melchers K and Hass R (2003) Identification and characterization of Helicobacter pylori genes essential for gastric colonization. J Exp Med 197, 813-822.

15. Keuntje B, Masepohl B and Klipp W (1995) Expression of the put $A$ gene encoding proline dehydrogenase from Rhodobacter capsulatus is independent of $\mathrm{NtrC}$ regulation but requires an Lrp-like activator protein. $J$ Bacteriol 177, 64326439.

16. Krishnan N and Becker DF (2005) Characterization of a bifunctional Put A homologue from Bradyrhizobium japonicum and identification of an active site residue that modulates proline reduction in the flavin adenine dinucleotide cofactor. Biochemistry 44, 9130-9139.

17. Ling M, Allen SW and Wood JM (1994) Sequence analysis identifies the proline dehydrogenase and $\Delta^{1}$-pyrroline-5caroboxylate domain of the multifunctional Escherichia coli Put A protein. $J$ Mol Biol 243, 950-956.

18. Markwell MAK, Hass SM, Tolbert NE and Bieber LL (1981) Protein determination in membrane and lipoprotein samples; manuals and automated procedures. Methods Enzymol 72, 1920-1931.

19. McNulty CAM and Dent JC (1987) Rapid identification of Campylobacter pylori by preformed enzymes. J Clin Microbiol 25, 1683-1686.

20. Mendz GL and Hazell SL (1993) Glucose phosphorylation in Helicobacter pylori. Arch Biochem Biophys 300, 522-525.

21. Mendz GL, Hazell SL and Burns BP (1993) Glucose utilization and lactate production by Helicobacter pylori. J Gen Microbiol 139, 3023-3028.

22. Nagata K, Nagata Y, Sato T, Fujino MA, Nakajima K and Tamura T (2003) L-serine, D- and L-proline and alanine as respiratory substrates of Helicobacter pylori: correlation between in vitro and in vivo amino acid levels. Microbiology 149, 2023-2030.

23. Nedenskov P (1994) Nutritional requirements for growth of Helicobacter pylori. Appl Environ Microbiol 60, 3450-3453.

24. Noach LA, Rolf TM and Tygat GN (1994) Electron microscopic study of association between Helicobacter pylori and gastric and duodenal mucosa. J Clin Pathol 47, 699-704.

25. Ohkusa TM, Yamamoto M, Kataoka K, Kyoi T, Ueda F, Fujimoto H, Sasabe M, Tamura Y, Hosoi H, Tokoi S, Sasaki N and Saito Y (1993) Electron microscopic study of intracellular junctions in human gastric mucosa with special references to their relationship to gastric ulcer. Gut 34, 86-89.

26. Olson JW and Maier RJ (2002) Molecular hydrogen as an energy source for Helicobacter pylori. Science 298, 17881790.

27. Parsonnet J, Friedman GD, Vandersteen DP, Chang Y, Vogelman JH, Orentreich N and Sibley RK (1991) Helicobacter pylori infection and the risk of gastric carcinoma. $N$ Engl $J$ Med 325, 1127-1131.

28. Reynolds DJ and Penn CW (1994) Characteristics of Helicobacter pylori growth in a defined medium and determination of its amino acid requirements. Microbiology 140, 26492656.

29. Sakagami T, Yamamoto N, Sashio H, Sawada Y, Tamura K, 
Fukuda Y, Tanida N and Shimoyama T (2000) Helicobacter pylori and carcinogenesis experiments. In: Helicobacter pylori Infection in Gastroduodenal Lesions, Vol. 2, $2^{\text {nd }}$ ed. (Pajares Garcia JM, Correa P and Peres Peres GI, eds.), pp295-303, Prous Science, Barcelona.

30. Straub PF, Reynolds PH, Althomsons S, Mett V, Zhu Y, Shearer G and Kohl DH (1996) Isolation, DNA sequence analysis and mutagenesis of a proline dehydrogenase gene (put A) from Bradyhizobium japonicum. Appl Environ Microbiol 62, 221-229.

31. Tuda M, Karita M and Nakazawa T (1993) Genetic transformation in Helicobacter pylori. Microbiol Immunol 37, 85-89.

32. Uemura N, Okamoto S, Yamamoto S, Matsumura N, Yama- guchi S, Yamakido M, Taniyama K, Sasaki N and Schlemper RJ (2001) Helicobacter pylori infection and the development of gastric cancer. $N$ Engl $J$ Med 354, 784-789.

33. van Amsterdam K and van der Ende A (2004) Nutrients released by gastric epithelial cells enhance Helicobacter pylori growth. Helicobacter 9, 614-621.

34. Vilchez S, Molina L, Ramos C and Ramos JL (2000) Proline catabolism by Pseudomonas putida: cloning characterization, and expression of the put gene in the presence of root exudates. J Bacteriol 182, 91-99.

35. Xia M, Zhu Y, Cao X, You L and Chen Z (1996) Cloning sequencing and analysis of a gene encoding Escherichia coli proline dehydrogenase. FEMS Microbiol Lett 127, 235-242. 